\title{
EFFECT OF MATING ON TERMINATING AGGREGATION DURING HOST COLONIZATION IN THE BARK BEETLE, Ips paraconfusus
}

\author{
J.A. BYERS \\ Department of Entomological Sciences \\ University of California \\ Berkeley, California 94720
}

(Received December 22, 1980; revised February 26, 1981)

\begin{abstract}
Attraction of male Ips paraconfusus to male-infested ponderosa pine logs was inhibited by volatiles from logs infested with mated males and females over an 8-day period in the field. The response of females during this time was not significantly inhibited by these volatiles. Synthesis of the male-specific pheromones, ipsenol and ipsdienol, appeared negligible after 8 days in males allowed to mate with 3 females in these logs while males alone contained levels of these pheromones at about half their maximum rate. The decline in pheromone production in mated males appears to result, at least in part, from a reduction in the activity of the biosynthetic system that converts the host monoterpene, myrcene, to ipsenol and ipsdienol. Mating and feeding have apparently no effect on the biosynthetic system that converts the host monoterpene, $(-)-\alpha$-pinene, to the pheromone, cisverbenol in either males or females. The reduced production and release of pheromones by males after mating appears to play a major function in the process of terminating the aggregation phase of host colonization.
\end{abstract}

Key Words-Ips paraconfusus, Coleoptera, Scolytidae, Pinus ponderosa, pheromone biosynthesis, bark beetle, myrcene, $\alpha$-pinene, ipsenol, ipsdienol, cis-verbenol, myrtenol, attractants, pheromones.

\section{INTRODUCTION}

The male Ips paraconfusus initiates an entrance tunnel and excavates a "nuptial" chamber primarily in the phloem layer of ponderosa pine. After host material has passed through his digestive tract, the fecal pellets become attractive (Wood and Bushing, 1963; Vité et al., 1963; Pitman et al., 1965; Wood et al., 1966). Male frass (fragments of host tissue and fecal pellets) 
contains 3 pheromones, ipsenol, ipsdienol, and cis-verbenol, which together are attractive to males and females (Silverstein et al., 1966a,b; Wood et al., 1968). Ipsenol and ipsdienol are synthesized from the host plant chemical, myrcene, in males only (Hughes, 1974; Byers et al., 1979; Hendry et al., 1980). cis-Verbenol is synthesized from another host plant chemical $(-)-\alpha$-pinene, in both sexes (Renwick et al., 1976). These pheromones accumulate in the hind gut upon exposure to vapors of the host plant chemicals. However, only ipsenol and ipsdienol can be readily detected by GLC in hindguts of males feeding in the host (Vité et al., 1972; Byers, 1981a). Logs infested with males and exposed to attacking beetles cease to be attractive after 10-18 days in the field (Wood and Vité, 1961; Vité and Gara, 1962; Vité et al., 1963) and virgin male frass produced after about 18 days is not attractive in the laboratory (Wood and Bushing, 1963; Borden, 1967).

The male I. paraconfusus is polygamous, permitting entry of about three females into the nuptial chamber, after which others seeking entry are not accepted (Barr, 1969). The attractiveness of logs infested with males may decrease when females join the male. For instance, Borden (1967) found in the laboratory that females were less responsive to gut extracts of fed males mated with two or three females than to gut extracts of fed unmated males. In addition, the normal decline in attraction of $I$. paraconfusus to naturally colonized logs (Wood and Vité, 1961) was found to decrease more rapidly when females were allowed to join nuptial chambers (Wood, personal communication). This is analogous to the observation of Anderson (1948) that the attraction of $I$. pini to logs with attacking males ceased "immediately" when an "excess" of females were supplied.

The previous studies did not determine whether the decline in response to male frass or infested logs was due to a decrease in production and release of attractants or to the release of inhibitors or both. The possibility that mated females may produce inhibitors has not been investigated nor has their production of $c$ s-verbenol during the colonization period. Furthermore, the effect of mating and/or feeding on the biosynthetic systems that produce the pheromones in males and in females has not been established. Thus, the objectives of this study were (1) to determine if the response of $I$. paraconfusus to male-infested logs in the field could be inhibited by volatiles from logs infested with mated males and females, (2) to quantify the pheromones produced in these mated males and females and in unmated males during the field attraction period, and (3) to compare the pheromone biosynthetic systems in mated feeding beetles of both sexes to emergent beetles.

METHODS AND MATERIALS

Test for Inhibition of the Response of I. paraconfusus to Male-Infested Logs by Mated Males and Females. A paired-trap test was performed in the 
Sierra National Forest, California, (900-1100 m elevation ) (August 25September 7,1978 ). The catch of I. paraconfusus on a sticky trap containing a $\log$ infested with 30 males and an uninfested log was compared to the catch on a sticky trap 11-12 m away containing a log infested with 30 males and a $\log$ infested with 30 males and 90 females that were allowed to mate. The trap consisted of two 6-mm mesh screen cylinders $(19 \mathrm{~cm}$ diam $\times 30.5 \mathrm{~cm}$ high) coated with Stickem Special ${ }^{\circledR}$ (Bedard and Browne, 1969) placed side by side $1.2 \mathrm{~m}$ above the ground.

I. paraconfusus adults were reared from naturally infested logging debris obtained from the Sierra National Forest at about 1000 m elevation (Browne, 1972). Logs about $14 \mathrm{~cm}$ diam $\times 28 \mathrm{~cm}$ long were cut from a tree and stored less than one month at $4^{\circ} \mathrm{C}$ before use. Males were introduced head-first into holes drilled in logs. Each log was wrapped with aluminum window screen which, in designated logs, allowed introduced females free access to all male holes but prevented their escape from the log. The screen also prevented the possibility of attack by beetles attracted to the trap. The uninfested log was drilled and screened.

Twenty-four hours after introducing the males, females were added to the appropriate logs at $8 \mathrm{AM}$ on the first trapping day and allowed to join the males in the nuptial chambers. The uninfested log and the male- and femaleinfested log were exchanged daily between traps of each pair while the male-infested logs remained in place. Three pairs of traps were tested initially but two pairs were removed after 4,8 , and 12 days to obtain beetles for GLC analysis. I. paraconfusus and Enoclerus lecontei (Coleoptera: Cleridae), a predator, were collected from the traps each day, cleaned of Stickem with mineral spirits, and their sex was determined in the laboratory. The paired trap catches of each day (August 26-September 2) were analyzed with the Wilcoxon test for combining data from several experiments or blocks (Lehmann, 1975) because the 20 trap pairs were not independent replicates. Binomial confidence limits for sex ratios of catch were determined (Byers and Wood, 1980).

Pheromones in Unmated Males and Mated Males and Females of $\mathrm{I}$. paraconfusus Feeding in Logs. Mated males and females (as judged by brood larvae in 12-day-old logs) and unmated males were removed from under the bark of the logs used in the test for inhibition after 4,8 , and 12 days. The mid-and hindguts of two groups of 12-15 unmated males, two groups of 12-15 mated males, and two groups of 20-30 mated females were dissected out on each date and each group was extracted with $0.2 \mathrm{ml}$ diethyl ether. Another log infested with 30 unmated males at the same time as the other logs, but not field tested, was dissected after $80 \mathrm{hr}$ and two groups of 12-15 hindguts were extracted as above.

The amounts of pheromones present in these gut extracts were analyzed by GLC $(3.6 \mathrm{~m} \times 2 \mathrm{~mm}$ ID glass column of Ultrabond II on 100/120 mesh at 
$105^{\circ} \mathrm{C}$ and $\mathrm{N}_{2}$ flow of $30 \mathrm{ml} / \mathrm{min} ; 1.8 \mathrm{~m} \times 2 \mathrm{~mm}$ ID glass column of $3 \%$ Apiezon L on 100/120 Gas Chrom Q at $100^{\circ} \mathrm{C}$ and $\mathrm{N}_{2}$ flow of $12 \mathrm{ml} / \mathrm{min}$ ). For quantification, authentic ipsenol, ipsdienol (each $>97 \%$ ) and cis-verbenol (95\%) (all Chem. Samples Co.) and myrtenol (>99\%, Aldrich) were compared to gut extracts for retention time and peak area. Linear regression and analysis of covariance (Snedecor and Cochran, 1967) were performed on the amounts of ipsenol and ipsdienol found in feeding males on days 4,8 , and 12 where linear relationships were indicated (Figure 1). The presence of host material in the gut was noted, and the number of males and females per nuptial chamber was recorded except after 12 days when galleries became intermixed. Confirmation of mating was noted in the 12-day male-female logs by the presence of brood larvae (1-2 stage instar).

To determine if plant terpenes or other factors in 12 to 14-day-old logs became limiting to pheromone biosynthesis, unmated males that had fed 12 days in logs in the field were dissected out and discarded. Newly emerged males then were introduced into adjacent unattacked areas of these logs for 3 days. These males were dissected out and four groups of 13 were extracted and analyzed by GLC as described above.

Biosynthesis of Pheromones from Host Plant Terpenes in Mated and Emergent 1. paraconfusus. The abilities of mated and emergent males and females to synthesize ipsdienol, ipsenol, cis-verbenol, and myrtenol from host plant chemicals were compared (August 11-25, 1979). Thirty males were introduced into each of two logs, the logs screened, and $48 \mathrm{hr}$ later each log

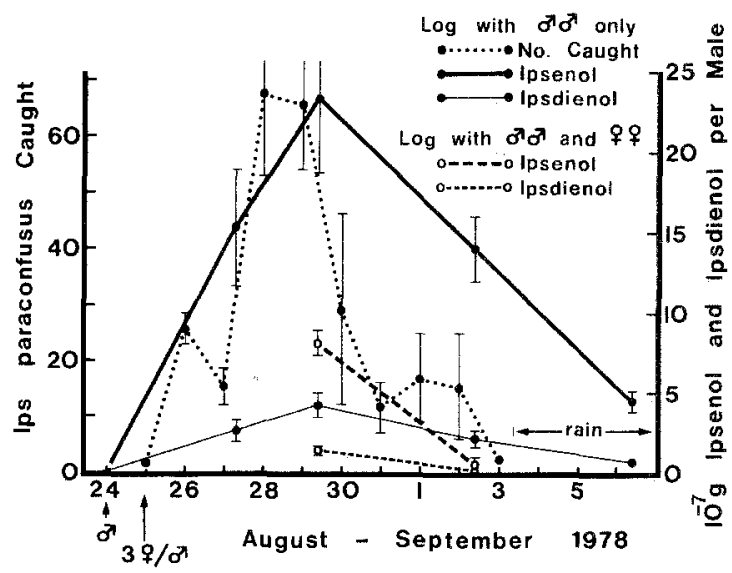

FIG. 1. Ipsenol and ipsdienol produced in mated and unmated male $I$. paraconfusus during feeding in logs and the average number of $I$. paraconfusus attracted to traps with logs infested with 30 unmated males in the Sierra National Forest. Brackets represent \pm SE $\bar{X}$. 
received 90 females as described above. The infested logs remained at $21 \pm 1.7^{\circ} \mathrm{C}$ for a total of 13 days after male introduction under natural light conditions. The beetles then were removed from the logs and four groups of 9 males and four groups of 9 females that had presumably mated were exposed to vapors of myrcene and $(-)-\alpha$-pinene, $\left[\alpha_{D}^{22}=-41.6^{\circ}\right.$ (both GLC purified $>99.8 \%$ ) in amber bottles for $18 \pm 0.5 \mathrm{hr}$ at $21 \pm 1.7^{\circ} \mathrm{C}$ (Byers et al., 1979). Ten $\mu$ l of each plant terpene was placed on glass filter paper inside each bottle and GLC analysis on the Apiezon $\mathrm{L}$ column showed that the headspace contained $1.7 \pm 0.2( \pm \mathrm{SE} \bar{X}) \times 10^{-6} \mathrm{~g}$ myrcene/ $\mathrm{ml}$ and $4.2 \pm 0.3 \times 10^{-6} \mathrm{~g}$ $(-)-\alpha$-pinene/ $\mathrm{ml}$. Mated males were not compared to unmated males that had fed for 13 days since these beetles contain even larger quantities of ipsenol and ipsdienol (Figure 1) than emergent beetles exposed to concentrations of precursor vapors similar to those tested above (Byers et al., 1979). Four groups of 9 unmated males and four groups of 9 unmated females that were refrigerated at $4^{\circ} \mathrm{C}$ during the 13-day period were exposed to terpene vapors as described above. Two additional control groups, 9 each of mated males and mated females from the logs, were placed in bottles for an equal time but not exposed to plant terpenes. All groups were extracted and analyzed by GLC for pheromones as described above. The $t$-tests were used to determine if differences in the quantity of ipsenol, ipsdienol, cis-verbenol, and myrtenol existed between mated and unmated beetles within each sex.

\section{RESULTS}

Test for Inhibition of the Response of I. paraconfusus to Male-Infested Logs by Mated Males and Females. The response of males, but not females, to a male-infested log was significantly lowered by the presence of a log infested with mated males and females (Table 1). However, the sex ratios of female to male catch on the paired traps were not significantly different, indicating that the inhibition of males was rather weak. The response of $E$. leconte $i$ was not significantly affected by volatiles released from the logs infested with mated males and females (Table 1).

Pheromones in Unmated Males and Mated Males and Females of I. paraconfusus Feeding in Logs. Emergent males introduced into 12-day-old logs contained $19.7 \pm 2.4( \pm$ SE $\bar{X}) \times 10^{-7} \mathrm{~g}$ ipsenol $/$ male and $3.7 \pm 0.5 \times$ $10^{-7} \mathrm{~g}$ ipsdienol $/$ male 3 days after introduction. These quantities are similar to those produced by other unmated males in fresh logs after about 3 days $(80 \mathrm{hr})$ (Figure 1). The increase in ipsenol and ipsdienol production in males feeding in logs was correlated with higher catches of I. paraconfusus (Figure 1). The catch may not have been proportional to the concentrations of pheromones in the guts because of variations in the daily abundance of responding beetles, differences in release of pheromones (defecation), and/or differences in wind 
TABle 1. CATCh of Ips paraconfusus AND Enoclerus lecontei on 20 PAIRED Traps Baited with logs Infested with Male and with Male and Female I. paraconfusus (August 26-September 2, 1978) in the Sierra National Forest

\begin{tabular}{|c|c|c|c|c|}
\hline \multirow[b]{3}{*}{$\begin{array}{l}\text { Sticky traps } \\
\text { containing }\end{array}$} & \multicolumn{4}{|c|}{ Catch } \\
\hline & \multirow[b]{2}{*}{ E. lecontei } & \multicolumn{3}{|c|}{ I. paraconfusus } \\
\hline & & $\sigma^{*}$ & ? & $\begin{array}{c}\text { Sex ratio } \\
(\mathrm{BCL})^{a}\end{array}$ \\
\hline \multicolumn{5}{|l|}{$30 \delta$ log plus } \\
\hline blank log & 231 & 176 & 492 & $\begin{array}{c}2.79^{b} \\
(2.35-3.32)\end{array}$ \\
\hline \multicolumn{5}{|l|}{30 ठ log plus } \\
\hline $300^{\star}+90 \log$ & 291 & 115 & 405 & $\begin{array}{c}3.52^{h} \\
(2.87-4.33)\end{array}$ \\
\hline $\begin{array}{l}P \text { value of } \\
\text { inhibition }^{c}\end{array}$ & 0.253 & 0.039 & 0.451 & \\
\hline
\end{tabular}

\footnotetext{
${ }^{a}$ Upper and lower $95 \%$ binomial confidence limits for sex ratio $\left(\% / 0^{*}\right)$.

${ }^{b}$ Sex ratios were not significantly different $P=0.092$ (Chi-square).

${ }^{c} P$ values $<0.05$ (two-sided) indicate a significant difference between the catch on the two treatments (Wilcoxon test).
}

and weather conditions (rained after September 3). cis-Verbenol was not detected in either males or females $\left(<0.5 \times 10^{-8} \mathrm{~g} /\right.$ beetle) feeding in logs.

Regression analysis of depletion of pheromone quantities in guts of unmated males indicated that they would produce and release negligible levels of ipsenol and ipsdienol after 14 days of feeding, assuming that production continued in a linear decline (from regression, Table 2). On the other hand, regression analysis of pheromones in guts of mated males showed that ipsenol and ipsdienol production and release was negligible only 8.3 days after females joined their nuptial chambers (Table 2). The mated males did not contain detectable levels $\left(<0.5 \times 10^{-8} \mathrm{~g} /\right.$ male) of any pheromone after 12 days of feeding. The quantities of ipsenol and ipsdienol produced by the mated males were significantly less than the unmated males during the period of observation as shown by the elevation difference of the respective regression lines (Table 2). All but one or two nuptial chambers were occupied by 1 male and 1-5 females with an average of $2.9 \pm 0.2$ and $2.8 \pm 0.2( \pm \operatorname{SE} \bar{X})$ females/male after 4 and 8 days, respectively. Mating was confirmed in the 12-day-old logs in which almost all females had produced larvae. There were no significant differences in the rate of decrease (slope) in production of ipsenol or ipsdienol between unmated males and males with females (Table 2). The ratio of ipsenol-ipsdienol production in unmated males, $6.3 \pm 0.3( \pm \mathrm{SE}$ $\bar{X}$ ), was nearly identical to the ratio in mated males, $6.5 \pm 0.5$. These ratios are 
Table 2. Comparison of linear Regression Lines of Quantities of Ipsenol and IPSDienol $\left(Y \times 10^{-7}\right.$ G/Male) in Hindguts of Male Ips paraconfusus FeEding in Logs With oR Without Females 4-12 days $(X)$ AFter INTRoduction of Females ${ }^{a}$

\begin{tabular}{lllll} 
& & & \multicolumn{2}{c}{$P$ value $^{b}$} \\
\cline { 4 - 5 } & \multicolumn{1}{c}{ Equation } & $r^{2}$ & $\begin{array}{c}\text { Slope } \\
\text { difference }\end{array}$ & $\begin{array}{c}\text { Elevation } \\
\text { difference }\end{array}$ \\
\hline $\begin{array}{c}\text { Ipsenol- } \\
\text { male only log }\end{array}$ & $Y=-2.35 X+32.7$ & 0.87 & & \\
$\begin{array}{c}\text { Ipsenol- } \\
\text { male with 3 } \\
\text { females log }\end{array}$ & $Y=-1.92 X+15.9$ & 0.97 & & $<0.001$ \\
$\begin{array}{c}\text { Ipsdienol- } \\
\text { male only log }\end{array}$ & $Y=-0.44 X+5.9$ & 0.86 & 0.48 & $<0.001$ \\
$\begin{array}{c}\text { Ipsdienol- } \\
\text { male with 3 } \\
\text { females log }\end{array}$ & $Y=-0.32 X+2.6$ & 0.95 & & \\
$\begin{array}{l}\text { Ipsenol- } \\
\text { male only log }\end{array}$ & $Y=-2.35 X+32.7$ & 0.87 & & \\
$\begin{array}{l}\text { Ipsdienol- } \\
\text { male only log }\end{array}$ & $Y=-0.44 X+5.9$ & 0.86 & 0.003 & \\
\hline
\end{tabular}

\footnotetext{
${ }^{a}$ See Figure 1.

${ }^{h} \mathrm{~A} P$ value $<0.05$ indicates a significant difference between slopes or elevations of regression lines of pheromones produced in feeding males (Analysis of Covariance).
}

similar to those reported in previous studies in which emergent males were exposed to myrcene vapors (5.9, Byers et al., 1979; 6.0, Byers and Wood, 1981). The significant difference in the decline in amounts of ipsenol compared to ipsdienol in unmated males (Table 2) is the result of the consistent ratio of synthesis of these pheromones at any precursor concentration, as shown by Byers et al. (1979).

Biosynthesis of Pheromones from Host Plant Terpenes in Mated and Emergent I. paraconfusus. Ipsenol and ipsdienol production was significantly less in fed, mated males than in unfed, unmated males when both were exposed to myrcene and (-)- $\alpha$-pinene (Figure 2). The mated males and females that had fed for 13 and 11 days, respectively, did not contain detectable levels of any pheromones after $18 \mathrm{hr}$ in a bottle without host terpenes. Unmated, emergent males that were refrigerated, instead of unmated, fed males, were compared to the mated, fed males because both groups do not contain detectable amounts of pheromone prior to terpene vapor exposure (Figure 1) (Byers et al., 1979). Mating and/or feeding appeared to have no effect on cis-verbenol and myrtenol production in either males or females (Figure 2). 


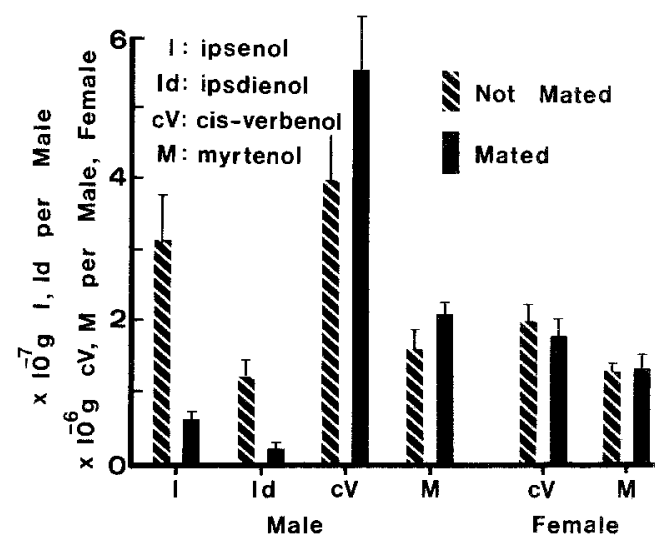

FIG. 2. Ipsenol, ipsdienol, cis-verbenol, and myrtenol produced in mated, fed males and in unmated, emergent males and females exposed to myrcene and $(-)-\alpha$-pinene vapors (August 25, 1979). Brackets above the bars represent + SE $\bar{X}$. A $t$ test showed that unmated males produced significantly more ipsenol $(P=0.007)$ and ipsdienol $(P=0.005)$ than mated males. There were no significant differences in the production of either cis-verbenol or myrtenol between mated and unmated males or between mated and unmated females $(P>0.1)$.

\section{DISCUSSION}

The decline in production of ipsenol and ipsdienol in both mated and unmated males (Figure 1) could be caused by one or more of the following mechanisms: (1) a reduction in the concentration of terpene precursors in aged logs, (2) a reduction in feeding, or (3) a change in the physiological condition of the beetle. The concentration of terpene precursors in 12- to 14-day-old logs may not be limiting pheromone production since newly emerged males feeding in these logs produced amounts of pheromone comparable to males in 3-day-old logs. However, the concentration of terpenes immediately surrounding nuptial chambers after 12-14 days might possibly have become limiting compared to adjacent areas because of volatilization and the action of microorganisms. A reduction in feeding by mated males compared to unmated males and a decline in feeding over time also might explain the decrease in production of pheromones, although all males and females, whether mated or unmated, had phloem in their hindguts. Wood et al. (1966) showed that the daily frass output of virgin males was about the same after 10-12 days as that after 2-3 days. However, the fecal pellet production may vary independently from frass output during the decline in attraction. Female defecation would make the quantification of fecal pellet production of mated males very difficult if not impossible. 
The decrease in the amounts of pheromones in mated and unmated males feeding in logs could also result from a change in the physiological condition during feeding and after mating. The abilities of the biosynthetic systems in mated and virgin, emergent males to produce pheromones were compared by exposure to vapors of $(-)-\alpha$-pinene and myrcene. This method circumvents possible feeding control over entry of these precursors into the intestine. Since mated males did not produce as much ipsenol and ipsdienol as unfed virgin males, a physiological change was indicated that could have been induced by effects of feeding and / or mating. However, physiological effects from feeding appear less likely since Byers and Wood (1981) found that male I. paraconfusus fed on a ground phloem and cellulose diet, low in plant terpenes, produced ipsenol, ipsdienol, and cis-verbenol in quantities not significantly different from that in unfed males when both groups were exposed to myrcene and $\alpha$-pinene vapors. Hughes and Renwick (1977) reported that feeding on host tissue may even enhance the biosynthetic system, although this effect may be due, at least in part, to increased availability of precursors (Byers, 1981a). Therefore, the reduction of ipsenol and ipsdienol production observed in mated males compared to unmated males during feeding in logs might be explained, at least in part, by a reduction in the activity of the mated male's biosynthetic system since physiological effects from feeding would be expected to be similar. Possible effects of mating and feeding did not appear to significantly influence the conversion of $(-)-\alpha$-pinene to cis-verbenol and myrtenol, so it may be that production of these compounds during host colonization does not decline after mating. However, cis-verbenol alone is not attractive to I. paraconfusus (Wood et al., 1968).

The bacterium, Bacillus cereus, isolated from hindguts of male and female $I$. paraconfusus, has been shown to synthesize cis-verbenol and myrtenol from $\alpha$-pinene (Brand et al., 1975). In the present study, the quantities of cis-verbenol and myrtenol produced during terpene exposure were similar in beetles before and after feeding, indicating that $B$. cereus was not affected by feeding or it is not the major producer of $c i s$-verbenol in the insect. Byers and Wood (1981) indicated the possibility of another symbiotic microorganism within the beetle since the antibiotic streptomycin, when fed to males, inhibited the production of ipsenol and ipsdienol during exposure to myrcene vapors, while the conversion of $\alpha$-pinene to cis-verbenol did not appear to be inhibited. Thus, further information on the presence, location, and metabolism of the suspected microsymbionts is needed to explain the effects of mating and feeding on pheromone production.

Hughes and Renwick (1977) hypothesized that gut stretching due to feeding stimulates the release of juvenile hormone $(\mathrm{JH})$ which was found to enhance ipsenol and ipsdienol synthesis during exposure of male 1 . paraconfusus to myrcene vapors. However, as noted earlier, Byers and Wood (1981) found that feeding on diets low in plant terpenes did not significantly 
affect pheromone production, indicating that gut stretching/feeding may not be required for pheromone synthesis. If $\mathrm{JH}$ is involved in pheromone synthesis, then JH levels may decline in males after mating, since mated, fed males did not produce as much ipsenol and ipsdienol as unmated, fed males (Figure 1) and unmated, unfed males (Figure 2). The capacity of the biosynthetic systems to produce ipsenol and ipsdienol in unmated, fed and in unmated, unfed males may be difficult to determine because fed males contain appreciable amounts of pheromones while unmated, unfed males contain no pheromones prior to vapor exposure (Byers et al., 1979).

The reduction in male catch from logs infested with mated males and females suggests that inhibitors may be released that lower the attraction of males, but not females, to their pheromones. If an as yet undiscovered inhibitor is involved in terminating aggregation, then I. paraconfusus would need to release it for at least several days after mating to inhibit response to the still significant amounts of ipsenol and ipsdienol in mated males during this period (Figure 1). Therefore, the test for inhibition was performed during the first 8 days when inhibitors, if they exist, would be required. On the other hand, Byers (1981b) found that males, but not females, were inhibited by higher release rates of ipsenol, ipsdienol, and cis-verbenol in the laboratory and that male response became proportionately less than female's as the beetles approached a natural pheromone source in the field. Therefore, in the present study, it may be that the males were inhibited by a higher release rate of male pheromone from the trap with 60 males ( 30 mated and 30 unmated) compared to the other trap with 30 unmated males.

After the female bark beetle, Dendroctonus pseudotsugae, is joined by a male, she may release 3-methyl-2-cyclohexene-1-one (MCH) which inhibits response to her attractants (Rudinsky and Michael, 1972; Rudinsky, 1973). In contrast, Pitman and Vité (1974) found that males contain considerably more $\mathrm{MCH}$ than females, and they believe the male predominates in the release of the inhibitor upon joining the female in her gallery. The attraction elicited by female ambrosia beetles of Trypodendron lineatum is inhibited by volatiles released from the male (Nijholt, 1973). These "antiattractants" or inhibitors lower the attraction of beetles to their pheromones but new attacks would still continue indefinitely unless attractant production declined or other mechanisms that limit density of attack operated.

The decline in pheromone production after mating in $I$. paraconfusus, which appears to function as part of the mechanism for terminating the aggregation phase of host colonization, also occurs in the smaller European elm bark beetle, Scolytus multistriatus and the southern pine beetle, $D$. frontalis. Coster and Vité (1972) found that the pheromones, frontalin and trans-verbenol, in the hindgut of $D$. frontalis declined rapidly during the first $48 \mathrm{hr}$ of feeding. Although statistical tests were not performed, mated females appeared to contain smaller amounts of these pheromones after $48 \mathrm{hr}$ than 
virgin females while attractive responses to these females were not significantly different. The attraction of $S$. multistriatus to female-infested elm logs declined after males were introduced (Peacock et al., 1971; Elliott et al., 1975). Elliott et al. (1975) provided evidence (but presented no statistics) that maleand female-infested elm logs did not appear to inhibit the attraction of $S$. multistriatus to female-infested logs. Gore et al. (1977) then showed that females ceased to produce (-)-4-methyl-3-heptanol, one of its pheromones, after mating. In I. paraconfusus, $D$. frontalis, and $S$. multistriatus, a decline in pheromone production and release after mating would not ensure the termination of mass attraction because later arriving beetles that had not mated yet would sustain the release of attractants. Therefore, additional mechanisms that regulate attack density such as territorial behavior or closerange inhibitors that would continue to be released after attractant production ceased are required to explain the entire process of termination of aggregation. These hypothetical mechanisms remain to be identified.

Acknowledgments - The support and use of research facilities of D. L. Wood, Department of Entomological Sciences, University of California at Berkeley, as well as those of W.D. Bedard and P.E. Tilden of the Forest Service, USDA, at Oakhurst, California, are greatly appreciated. I am grateful to P.R. Akers, A.M. Liebhold, D.R. Owen, and D.L. Wood, Department of Entomological Sciences, University of California at Berkeley, and J.S. Elkinton, Department of Entomology, University of Massachusetts for helpful reviews of the manuscript. The work was supported in part by grants from the Rockefeller Foundation, US Forest Service, and Regional Research Project W-110, SEA/USDA (to D.L.W.).

\section{REFERENCES}

ANDERSON, R.F. 1948. Host selection by the pine engraver. J. Econ. Entomol. 41:596-602.

BARR, B.A. 1969. Sound production in Scolytidae (Coleoptera) with emphasis on the genus Ips. Can. Entomol. 101:636-672.

BEDARD, W.D., and BROWNE, L.E. 1969. A delivery-trapping system for evaluating insect chemical attractants in nature. J. Econ. Entomol. 62:1202-1203.

BORDEN, J.H. 1967. Factors influencing the response of Ips confusus (Coleoptera: Scolytidae) to male attractant. Can. Entomol. 99:1164-1193.

Brand, J.M., Bracke, J.W., Markovetz, A.J., Wood, D.L., and Browne, L.E. 1975. Production of verbenol pheromone by a bacterium isolated from bark beetles. Nature 254:136-137.

BRoWNE, L.E. 1972. An emergence cage and refrigerated collector for wood-boring insects and their associates. J. Econ. Entomol. 65: 1499-1501.

BYERs, J.A. 1981a. Pheromone biosynthesis in the bark beetle, Ips paraconfusus, during feeding or exposure to vapours of host plant precursors. Insect Biochem. In press.

BYERS, J.A. 1981b. Regulation of colonization density of the bark beetle, Ips paraconfusus, by sex-specific responses to pheromone. Anim. Behav. Submitted.

BYERS, J.A., and WOOD, D.L. 1980. Interspecific inhibition of the response of the bark beetles Dendroctonus brevicomis and Ips paraconfusus to their pheromones in the field. J. Chem. Ecol. 6:149-164.

Byers, J.A., and Wood, D.L. 1981. Antibiotic-induced inhibition of pheromone synthesis in a bark beetle. Science. 213:763-764. 
Byers, J.A., Wood, D.L., Browne, L.E., Fish, R.H., Piatek, B., and Hendry, L.B. 1979. Relationship between a host plant compound, myrcene and pheromone production in the bark beetle Ips paraconfusus. J. Insect Physiol. 25:477-482.

Coster, J.E., and VITÉ, J.P. 1972. Effects of feeding and mating on pheromone release in the southern pine beetle. Ann. Entomol. Soc. Am. 65:263-266.

ElifotT, E.W., LANier, G.N., and Simeone, J.B. 1975. Termination of aggregation by the European elm bark beetle, Scolytus multistriatus. J. Chem. Ecol. 1:283-289.

Gore, W.E., Pearce, G.T., Lanier, G.N., Simeone, J.B., Silverstein, R.M., Peacock, J.W., and Cuthbert, R.A. 1977. Aggregation attractant of the European elm bark beetle, Scolytus multistriatus: Production of individual components and related aggregation behavior. $J$. Chem. Ecol. 3:429-446.

Hendry, L.B., Piatek, B., Browne, L.E., Wood, D.L., Byers, J.A., Fish, R.H., and Hicks, R.A. 1980. In vivo conversion of a labelled host plant chemical to pheromones of the bark beetle Ips paraconfusus. Nature 284:485.

Hughes, P.R. 1974. Myrcene: A precursor of pheromones in ips beetles. J. Insect Physiol. 20: $1271-1275$.

Hughes, P.R., and Renwick, J.A.A. 1977. Neural and hormonal control of pheromone biosynthesis in the bark beetle Ips paraconfusus. Physiol. Entomol. 2:117-123.

Lehmann, E.L. 1975. Nonparametrics: Statistical Methods Based on Ranks. Holden-Day, San Francisco.

Nijholt, W.W. 1973. The effect of male Trypodendron lineatum (Coleoptera: Scolytidae) on the response of field populations to secondary attraction. Can. Entomol. 105:583-590.

Peacock, J.W., Lincoln, A.C., Simeone, J.B., and Silverstein, R.M. 1971. Attraction of Scolytus multistriatus (Coleoptera: Scolytidae) to a virgin-female-produced pheromone in the field. Ann. Entomol. Soc. Am. 64:1143-1149.

Pitman, G.B. and Viré, J.P. 1974. Biosynthesis of methylcyclohexenone by male Douglas-fir beetle. Environ. Entomol. 3:886-887.

Pitman, G.B., Kliefoth, R.A., and VitÉ, J.P. 1965. Studies on the pheromone of Ips confusus (LeConte). II. Further observations on the site of production. Contrib. Boyce Thompson Inst. 23:13-17.

Renwick, J.A.A., Hughes, P.R., and KrulL, I.S. 1976. Selective production of cis- and trans-verbenol from $(-)$ and $(+)$ alpha-pinene by a bark beetle. Science 191:199-201.

Rudinsky, J.A. 1973. Multiple functions of the Douglas fir beetle pheromone 3-methyl-2cyclohexene-1-one. Environ. Entomol. 2:579-585.

Rudinsky, J.A., and MiChael, R.R. 1972. Sound production in Scolytidae; Chemostimulus of sonic signal by the douglas-fir beetle. Science 175:1386-1390.

Silverstein, R.M., Rodin, J.O., and WoOD, D.L. 1966a. Sex attractants in frass produced by male Ips confusus in ponderosa pine. Science 154:509-510.

Silverstein, R.M., Rodin, J.O., WoOD, D.L., and Browne, L.E. 1966b. Identification of two new terpene alcohols from frass produced by Ips confusus in ponderosa pine. Tetrahedron 22: 1929-1936.

SnedeCoR, G.W., and Cochran, W.G. 1967. Statistical Methods, 6th ed., lowa State University Press, Ames, Iowa.

VITÉ, J.P., and GARA, R.I. 1962. Volatile attractants from ponderosa pine attacked by bark beetles (Coleoptera: Scolytidae). Contrib. Boyce Thompson Inst. 21:251-274.

VITÉ, J.P., GARA, R.I., and KLIEFOTH, R.A. 1963. Collection and bioassay of a volatile fraction attractive to Ips confusus (LeC.) (Coleoptera: Scolytidae). Contrib. Boyce Thompson Inst. 22:39-50.

Vité, J.P., BAKKe, A., and Renwick, J.A.A. 1972. Pheromones in Ips (Coleoptera: Scolytidae): Occurrence and production. Can. Entomol. 104:1967-1975.

WooD, D.L., and Bushing, R.W. 1963. The olfactory response of Ips confusus (LeConte) 
(Coleoptera: Scolytidae) to the secondary attraction in the laboratory. Can. Entomol. 95: 1066-1078.

WoOD, D.L. and VITÉ, J.P. 1961. Studies on the host selection behavior of Ips confusus (LeConte) (Coleoptera: Scolytidae) attacking Pinus ponderosa. Contrib. Boyce Thompson Inst. $21: 79-96$.

Wood, D.L., Browne, L.E., Silverstein, R.M., and Rodin, J.O. 1966. Sex pheromones of bark beetles-I. mass production, bioassay, source, and isolation of the sex pheromone of Ips confusus (LeC.). J. Insect Physiol. 12:523-536.

Wood, D.L., Browne, L.E., Bedard, W.D., Tilden, P.E., Silverstein, R. M., and Rodin, J.O. 1968. Response of Ips confusus to synthetic sex pheromones in nature. Science 159: 1373-1374. 